\title{
Eure-et-Loir (partie nord du département)
}

$n^{\circ} 064431$

\section{Régis Dodin}

\section{(2) OpenEdition \\ Journals}

Édition électronique

URL : http://journals.openedition.org/adlfi/13993

ISSN : 2114-0502

Éditeur

Ministère de la culture

Référence électronique

Régis Dodin, "Eure-et-Loir (partie nord du département) », ADLFI. Archéologie de la France - Informations [En ligne], Centre, mis en ligne le 23 janvier 2015, consulté le 01 mai 2019. URL : http:// journals.openedition.org/adlfi/13993

Ce document a été généré automatiquement le 1 mai 2019.

(C) Ministère de la Culture et de la Communication, CNRS 


\title{
Eure-et-Loir (partie nord du département)
}

$n^{\circ} 064431$

\author{
Régis Dodin
}

1 À la fin du printemps et au début de l'été, de longues journées d'ensoleillement succédant à des pluies relativement peu abondantes ont permis la révélation d'un grand nombre de sites archéologiques sur les sols argileux du Drouais et du Thimerais dans la période pendant laquelle nous avons effectué nos survols, fin juin-début juillet, à la maturité des moissons.

2 La liste que nous donnons ci-dessous n'est pas exhaustive. Nous nous limitons à citer, dans ce rapport, les résultats qui nous paraissent les plus remarquables. Un recueil de fiches vient en complément.

\section{Zones archéologiques sensibles}

De nombreuses structures archéologiques (villae, enclos, etc...) apparaissent très souvent dans une couverture végétale qui révèle un sol très hétérogène dont la texture argilohumide a été modifiée par des apports importants de sels minéraux et de matière organique que la communauté vivant sur place a véhiculée. De ce fait, le sol est devenu un milieu peu favorable à la croissance et au développement des végétaux cultivés. Dès les premières journées d'été chaudes et sèches, les plantes jaunissent très vite et entrent dans un processus de dessication irréversible avant même leur maturité; seules les plantes bénéficiant des réserves d'eau que retiennent les fossés et les fosses comblés, et les plaques de limon riches en humus peuvent rester vertes. Ces plantes vertes, liées aux structures conservatrices de fraîcheur révèlent d'autant mieux celles-ci que le fond est particulièrement aride. Quand les fosses sont nombreuses, la couverture végétale prend un aspect très bariolé et, sous un éclairage rasant, apparaissent les discontinuités dans la croissance des végétaux liées aux discontinuités du sol. 
4 Nous avons pu constater que toutes les zones à dessiccation rapide que l'on repère facilement dans notre région céréalière sont presque toujours des aires anciennes d'habitat même si les traces du passage des hommes n'y sont pas toujours évidentes au premier abord. En fait il y a presque toujours quelques fosses ou fossés pour l'attester. Au début de cet été 1999 nous avons pu situer un certain nombre de ces aires. Nous citerons seulement quelques exemples :

- les Glands, commune de Chêne - Chenu

- la Villeneuve, commune de Saint-Rémy-sur-Avre

- la Vallée aux Malades, commune de Boissy-en-Drouais

- les Basselets, commune de Vérigny

- la Dimerie, commune de Boulay-Mivoie

\section{Villae gallo-romaines}

5 Les plans des fondations de trois villa, dont on connaissait l'existence par des prospections de surface et des clichés sommaires, se sont révélés de façon remarquable :

- la Henrière, commune de Chuisnes

- la Henrière, commune de Fontaine-la-Guyon

- les Châtelets, commune de Garancières-en-Drouais

6 A Fontaine-la-Guyon, la pars urbana présente un péristyle devant le corps d'habitation et un long mur de clôture la sépare de la pars rustica dans laquelle apparaissent des bâtiments importants. Cette villa est parmi les plus importantes du nord du département d'Eure-et-Loir.

\section{Granges gallo-romaines}

7 Sur la commune de Boissy-en-Drouais, au lieu-dit des Hutereaux est apparu le plan des fondations d'un bâtiment rectangulaire caractéristique des granges gallo-romaines (des fragments de tegulae au sol confirment la datation). Cette grange isolée, située à proximité d'une ancienne voie romaine, le Vieux Chemin de Verneuil, est entourée d'un fossé et le tout est inclus dans un enclos polygonal de quelques dizaines de mètres de large.

8 Au lieu-dit du Buisson Pouilleux (commune de Briconville), on retrouve une grange isolée également incluse dans un enclos polygonal.

\section{Enclos quadrangulaires}

9 A la liste, déjà longue, de ces enclos sont venus s'en ajouter d'autres cette année. Nous n'en citons que quelques-uns parmi les plus importants :

- la Pièce du Chainet, commune de Pontgoin, enclos parfaitement rectangulaire partiellement enveloppé dans une courbe semi-circulaire. 
- le Bois de la Canillée, commune de Mainterne-Crucey-Villages, enclos rectangulaire à l'intérieur d'une clairière cultivée et à proximité du Chemin Perret, une ancienne voie romaine de Condé-sur-Iton à Chartres.

10 Plusieurs enclos ont déjà été répertoriés dans les environs, notamment sur la commune de Vitray, associés à des sites de métallurgie du fer.

- la Villeneuve, commune de Favières, enclos sub-rectangulaire aux côtés légèrement curvilignes.

\section{Fossés en anneau}

De larges fossés formant des anneaux ouverts se sont révélés en trois endroits différents :

- le Poirier Michaud, commune de Thimert.

- la Fosse Colin, commune de Vert-en-Drouais.

- la Butte du Moulin, commune d'Ardelles.

12 La toponymie du site d'Ardelles est révélatrice ; il s'agit, sans doute dans les trois cas (tout à fait identiques), de buttes arasées ayant porté des moulins à vent et non de structures funéraires protohistoriques.

\section{Motte castrale}

13 Sur le territoire de la commune de Thimert, aux abords immédiats de la ville de Châteauneuf-en-Thimerais, s'est révélée une grande structure fossoyée dans laquelle il est facile de reconnaître le plan d'une motte féodale arasée d'une centaine de mètres selon son plus grand axe. En surface, une légère proéminence subsiste et le sol a visiblement été perturbé, des mottes d'argile ayant été ramenées en surface. Il est probable que cette fortification soit celle où Guillaume, duc de Normandie, fut assiégé par le roi de France, Henri I ${ }^{\mathrm{er}}$, en 1049. On sait que le roi de France fit araser la motte pour éviter que les Normands s'y installent à nouveau.

INDEX

Index géographique : Centre, Eure-et-Loir (28)

operation Prospection aérienne (PA)

Mots-clés : habitat, villa, grange, enclos 